\title{
Vertical price transmission in the US beef sector: \\ Evidence from the nonlinear ARDL model
}

\author{
Panos Fousekis ${ }^{\mathrm{a}}$, Constantinos Katrakilidis ${ }^{\mathrm{b}}$ and Emmanouil Trachanas ${ }^{\mathrm{c}, *}$ \\ ${ }^{a}$ School of Economics and Finance, Massey University, Palmerston North 4442, New \\ Zealand. Email: p.fousekis@massey.ac.nz \\ ${ }^{\mathrm{b}}$ Department of Economics, Aristotle University of Thessaloniki, Thessaloniki 54124, \\ Greece. Email: katrak@econ.auth.gr \\ c,* Department of Accounting, Finance and Economics, Oxford Brookes University, \\ Oxford OX33 1HX, UK. Corresponding author, Email: etrachanas@brookes.ac.uk
}

\begin{abstract}
The objective of this work is to investigate vertical price transmission in the US beef sector. To this end, it employs the Nonlinear ARDL model which allows prices to be tied by asymmetric relationships both in the long- as well as in the short-run. The empirical results indicate the presence of asymmetry in magnitude for the pair of markets farmwholesale and the presence of both asymmetry in speed and asymmetry in magnitude for the pair of markets wholesale-retail. The difference between the long-run elasticities of price transmission is more important from the wholesale to retail level than from the farm to the wholesale level.
\end{abstract}

Keywords: US Beef Sector, Asymmetric Price Transmission, Nonlinear ARDL model JEL Classification: Q11, C22

Acknowledgements: The authors are grateful to the journal's referees for providing valuable comments, which substantially improved this article. Emmanouil Trachanas acknowledges financial support from the Research Committee of the Aristotle University of Thessaloniki. 


\section{Introduction}

The analysis of vertical price linkages has been an important topic in agricultural economics research for almost 50 years. This is not accidental since the extent and/or the ease at which shocks are transmitted from one market level to another has potentially important welfare and policy implications. Following the initial work of Tweeten and Quance (1969), there has been a very large number of empirical studies on price relationships along agri-food chains (e.g. Wolffram, 1971; Houck, 1977; Ward, 1982; Kinnucan and Forker, 1987; von Cramon-Taubadel and Fahlbusch, 1994; Zhang, et al., 1995; Tiffin and Dawson, 2000; Goodwin and Harper, 2000; Abdulai, 2002; Serra and Goodwin, 2003; Lass, 2005; Ben-Kaabia and Gil, 2007; Gervais, 2011). ${ }^{1}$

Earlier works on price transmission asymmetry relied on the so called precointegration techniques where limited (if any) attention was placed on the time-series properties of the variables under investigation. More recent approaches have evolved around the notions of integration and cointegration in order to avoid potential spurious regression results and/or loss of relevant information about common trends observed by prices. Von Cramon-Taubadel and Fahlbusch (1994) suggested that, in case of cointegration, an Error Correction Model (ECM) distinguishing between positive and negative error correction terms provides an appropriate specification for testing asymmetric price transmission, vertical or horizontal/spatial one. Since then, several variants of the asymmetric ECM model have been employed in empirical studies including the Threshold Vector Error Correction Model (TVECM) which allows not only the sign but also the magnitude of the error correction terms to impact on price transmission (e.g. Goodwin and Holt, 1999; Ben-Kaabia and Gil, 2007).

Vertical asymmetric price transmission (APT) can be of two main types: (a) APT in magnitude and (b) APT in speed (Frey and Manera, 2007; Gervais, 2011). The former refers to magnitude of the price response at a given market level conditional on the direction of change of the price in another market level; the latter refers to the pace of price response at a given market level conditional on the direction of change of the price in another market level. Azzam (1999) and Xia (2009) have shown that, under market

\footnotetext{
${ }^{1}$ For extensive reviews on asymmetric price transmission see Meyer and von Cramon-Taubadel (2004) and Varva and Goodwin (2005).
} 
power, the APT in magnitude is associated with the second derivatives of the underlying input supply and output demand functions. The APT in speed has been largely attributed to the presence of transaction costs, menu costs, inventory management practices, and market power as well (Meyer and von Cramon-Taubadel, 2004).

The asymmetric ECM and the TVECM can be used to investigate APT in speed only $^{2}$. The reason is that those models maintain the hypothesis of a linear price relationship at the long-run equilibrium. The APT in magnitude, however, implies different long-run responses between positive and negative shocks (i.e., a nonlinear longrun price equilibrium). As noted by Gonzalo and Pitarakis (2006) if the maintained hypothesis is not true, the asymmetric ECM and TVECM can lead to misleading estimates not only for the long-run relationship but for the adjustment process that leads to it (i.e. for the speed of adjustment/the short-run asymmetry) as well. Gervais (2011) proposed a framework to separate non linearity in the long-run price relationship from that in the adjustment path towards the long-run equilibrium. This framework involves two steps. In the first, one tests the null of a linear long-run equilibrium against the alternative of a Smooth Transition Cointegration one (Choi and Saikkonen, 2004). In the second, the residuals of the selected model are tested for the presence of nonlinearity. An application to the US pork supply chain provided evidence of asymmetry in the long-run (APT in magnitude) and of symmetry in the short-run (no APT in speed). More importantly, the empirical results of Gervais (2011) indicated that failure to account for ATP in magnitude may wrongly lead to the conclusion of short-run asymmetry.

Gervais (2011) contribution is certainly valuable. The empirical implementation of the Smooth Transition Cointegration model (where the relationship between prices at different market levels changes according to some transition mechanism which depends on prices) is not easy. The smoothness parameter of the involved logistic function is typically estimated with very low precision, while conventional inference for a number of coefficients is difficult to carry out because the respective null hypotheses involve nuisance parameters.

In this context, the objective of the present work is to investigate vertical price transmission in the US beef supply chain. The US beef cattle production represents the

\footnotetext{
${ }^{2}$ The same is true for the Markov-switching ECM.
} 
largest single segment of American agriculture ${ }^{3}$ and has been the object of frequent attention from economists and policy makers due to very high levels of concentration (especially in beef packing) as well as due to certain buyer strategies (e.g. captive supplies, long-term contracts, marketing agreements, and packer ownership of cattle). Concerns have been often expressed that concentration has rendered conditions more conductive to the exercise of market power and that the alternative marketing arrangements have attenuated processors' incentives to bid in spot markets reducing, in this way, prices at the farm level (e.g. GIPSA, 2007; Ward, 2010; Saitone and Sexton, 2012).

The investigation here is based on the Nonlinear ARDL (NARDL) cointegration approach (Shin et al., 2014) which relies on positive and negative partial sum decompositions of the variables of interest. The NARDL model is relatively easy to implement; it allows for the joint analysis of non-stationarity and non-linearity and, more importantly, for the detection of asymmetric effects both in the long- as well as in the short-run (i.e., for the separation of APT in magnitude from APT in speed). NARDL models have been employed (among others) by Delatte and Lopez-Villavicencio (2012) to analyze exchange rate pass-through, by Katrakilidis and Trachanas (2012) to investigate housing price dynamics, by Greenwood-Nimmo and Shin (2013a) and Atil et al. (2014) to identify asymmetric price transmission in energy markets, and by Verheyen (2013) to analyze the determinants of bilateral exports between the US and EMU countries. To the best of our knowledge, there has been no published work on asymmetric price transmission in food markets using the NARDL cointegration approach.

In what follows, section 2 presents the analytical framework and section 3 the data, the empirical models and the empirical results. Section 4 offers conclusions.

\section{The Analytical Framework}

The standard linear ARDL $(p, q)$ cointegration model (Pesaran and Shin, 1999; Pesaran et al., 2001) with two time series $y_{t}$ and $x_{t}(t=1,2, \ldots, T)$ has the following form:

$$
\Delta y_{t}=a_{0}+\rho y_{t-1}+\theta x_{t-1}+\gamma z_{t}+\sum_{j=1}^{p-1} a_{j} \Delta y_{t-j}+\sum_{j=0}^{q-1} \pi_{j} \Delta x_{t-j}+e_{t}
$$

\footnotetext{
${ }^{3}$ http://www.bseinfo.org/beefindustryfacts.aspx
} 
where $z_{t}$ is a vector of deterministic regressors (trends, seasonals, and other exogenous influences, with fixed lags) and $u_{t}$ is an iid stochastic process. Under the null hypothesis (i.e., $y_{t}$ and $x_{t}$ are not cointegrated), the coefficients of the lagged levels of those two variables in Equation (1) are jointly zero $(\rho=\theta=0)$. Pesaran et al. (2001) showed that the assumption of no cointegration can be tested either by means of a modified $F$-test, denominated $F_{P S S}$ or (for the cases that certain classical assumptions are violated) by means of a Wald-test, denominated $W_{P S S}$. The test procedure relies on two critical bounds; the upper and the lower one. If the empirical values of the $F_{P S S}$, the $W_{P S S}$ statistics exceed the upper bound, the null is rejected (there is evidence of a long-run equilibrium relationship between $y_{t}$ and $x_{t}$ ); if they lie below the lower bound, $y_{t}$ and $x_{t}$ are not cointegrated; if they lie between the critical bounds the test is inconclusive.

Alternatively, the null hypothesis of no cointegration can be assessed by means of the $t_{B D M}$ test (Banerjee et al., 1998) suitable for testing $\rho=0$ (no cointegration) against $\rho<0$ (cointegration). The $t_{B D M}$ test also relies on two critical bounds (the upper and the lower one). If the empirical value of $t_{B D M}$ statistic exceeds the upper bound, the null is rejected; if it lies below the lower bound, the null is not rejected; if it lies between the bounds the test is inconclusive.

The ARDL approach to cointegration testing has several interesting characteristics. First, it performs better to small samples compared to alternative multivariate cointegration procedures. Second, it is more efficient than the standard Engle and Granger two step approach (typically employed in estimating asymmetric EC and TVEC models). Third, it does not require the restrictive assumption that all series are integrated of the same order allowing for the inclusion of both $I(0)$ and $I(1)$ (but not I(2) ) time series in a long-run relationship; this not only provides considerable flexibility but it also avoids potential "pre-test bias", that means, specification of a longrun model on the basis of I(1) variables only (e.g. Pesaran et al., 2001; Romilly et al., 2001).

The combination of stochastic regressors in the standard ARDL approach is linear, implying symmetric adjustments in the long- and the short-run. To account for 
asymmetries Shin et al. (2014) introduced the NARDL model in which $x_{t}$ is decomposed into its positive and negative partial sums (Shin et al., 2014), that is,

$x_{t}=x_{0}+x_{t}^{+}+x_{t}^{-}$

where

$x_{t}^{+}=\sum_{j=1}^{t} \Delta x_{j}^{+}=\sum_{j=1}^{t} \max \left(\Delta x_{j}, 0\right)$ and $x_{t}^{-}=\sum_{j=1}^{t} \Delta x_{j}^{-}=\sum_{j=1}^{t} \min \left(\Delta x_{j}, 0\right)$

Then, the asymmetric long-run equilibrium relationship can be expressed as:

$y_{t}=\beta^{+} x_{t}^{+}+\beta^{-} x_{t}^{-}+u_{t}$

where $\beta^{+}$and $\beta^{-}$are the asymmetric long-run parameters associated with positive and negative changes in $x_{t}$, respectively. Shin et al. (2014) showed that by combining (4) with the $\operatorname{ARDL}(p, q)$ model $(1)$ we obtain the $\operatorname{NARDL}(p, q)$ model as:

$$
\Delta y_{t}=a_{0}+\rho y_{t-1}+\theta^{+} x_{t-1}^{+}+\theta^{-} x_{t-1}^{-}+\sum_{j=1}^{p-1} a_{j} \Delta y_{t-j}+\sum_{j=0}^{q-1}\left(\pi_{j}^{+} \Delta x_{t-j}^{+}+\pi_{j}^{-} \Delta x_{t-j}^{-}\right)+e_{t}
$$

where $\theta^{+}=-\rho / \beta^{+}$and $\theta^{-}=-\rho / \beta^{-}$.

The empirical implementation of a NARDL model involves four steps. The first, is to estimate (5) by standard OLS. The second, is to verify the existence an asymmetric cointegrating relationship between the levels of the series $y_{t}, x_{t}^{+}$, and $x_{t}^{-}$. Under the approach proposed by Shin et al. (2014), the null hypothesis of no cointegration ( $\left.\rho=\theta^{+}=\theta^{-}=0\right) \quad$ can be tested using the $F_{\text {PSS }}\left(W_{\text {PSS }}\right)$ statistic; under the approach proposed by Banerjee et al., 1998 the null hypothesis of no cointegration $(\rho=0)$ can be tested using the $t_{B D M}$ statistic. The third, is to test for long- and for short-run symmetry. For long-run symmetry, the relevant null hypothesis takes the form $\beta^{+}=\beta^{-}$(i.e. $\left.-\theta^{+} / \rho=-\theta^{-} / \rho\right)$ and it is tested by means of a standard Wald test. For short-run symmetry, the relevant null hypothesis can take either of the following two forms, the pairwise (strong-form) symmetry requiring $\pi_{j}^{+}=\pi_{j}^{-}$for all $j=1, \ldots, q-1$ or the additive (weak-form) symmetry requiring $\sum_{j=0}^{q-1} \pi_{j}^{+}=\sum_{j=0}^{q-1} \pi_{j}^{-}$. These hypotheses are tested by means of a standard Wald test as well. Provided that there is asymmetry (either in the long-run or in the short-run or in both), the fourth step involves the derivation of the 
positive and negative dynamic multipliers associated with unit changes in $x_{t}^{+}$and $x_{t}^{-}$. These are calculated as

$m_{h}^{+}=\sum_{j=0}^{h} \frac{\partial y_{t+j}}{\partial x_{t}^{+}} \quad$ and $\quad m_{h}^{-}=\sum_{j=0}^{h} \frac{\partial y_{t+j}}{\partial x_{t}} \quad$ with $h=0,1,2, \ldots$

for $x_{t}^{+}$and $x_{t}^{-}$, respectively. Note that as $h \rightarrow \infty$, then $m_{h}^{+} \rightarrow \beta^{+}$and $m_{h}^{-} \rightarrow \beta^{-}$.

Depicting and analyzing the paths of adjustment and/or the duration of the disequilibrium following initial positive or negative perturbations in prices, $m_{h}^{+}$and $m_{h}^{-}$adds useful information to the long- and short-run patterns of asymmetry.

\section{The Data, the Empirical Models, and the Empirical Results}

The data for the empirical analysis come from the Economic Research Service of the United States Department of Agriculture (ERS-USDA). These are monthly ${ }^{4}$ prices expressed in cents per pound (retail weight equivalent) at the farm, at the wholesale and at the retail level and they refer to the period 1990:1 to 2014:1. ${ }^{5}$ Fig. 1 presents the natural logarithms of the prices at the three levels of the US beef supply chain. All price series exhibit upward trends which are more pronounced since the late 1990s. Also, the volatility of prices at the farm and the wholesale level appear to be much higher than at the retail level.

[Figure 1 about here]

Tables 1 and 2 present the Phillips-Perron (1988) and the DF-GLS (Elliot et al., 1996) unit root tests, and the Zivot-Andrews (1992) and Lee-Strazicich (2004) unit root

\footnotetext{
${ }^{4}$ Recent studies (e.g. Narayan and Sharma, 2015) show that hypothesis tests may be frequency dependent. Data of higher frequency (e.g. weakly) are not available while data of lower frequency (e.g. annual) will result in a very small number of observations. Empirical studies on price transmission analysis rely typically on monthly data. Balcombe et al. (2007), Ghoshray (2010) and Barrett and Li (2002) argue that traders of agricultural and food commodities are more likely to respond to price signals within a month.

${ }^{5}$ Data on prices at the three levels of the beef supply chain are available from 1970 onwards. In the 1980s, however, the US beef industry underwent a structural change that took the form of increased concentration in beef packing (primarily) and in cattle feeding as well (e.g. Baily et al, 1995; Ward, 2010); in beef packing the CR4 rose from 0.3 in 1980 to 0.7 in 1990 while, at the same time, commercial feedlots gained considerable importance relative to farm feedlots. The developments in the industry between 1980 and 1990 suggest that price relationships along the beef supply chain in the early periods are not likely to be very informative compared to those in the most recent periods. On the basis on the above considerations, the present paper focusses its attention on price transmission after 1990.
} 
tests with one structural break, respectively. The results suggests that prices along the beef supply chain are $I(1)$.

[Table 1 and 2 about here]

A relevant issue in the empirical investigation of price transmission asymmetry is the selection of the so called causal markets (i.e. markets at which prices are established). In a number of works, the direction of causality is defined ad hoc based on certain characteristics of the market or some theoretical model. It is usually assumed that the price is established at the farm level and it flows forward to the wholesale and then to the retail level (e.g. Kinnucan and Forker, 1987; Lass, 2005; Gervais, 2011). A common explanation for the choice has been that supply shocks are more frequent than demand shocks and that sellers adopt fixed mark-up pricing. Other researchers identify the casual market by employing some type of causality or exogeneity test. Although much of the empirical evidence appears to support uni-directional causality from the farm to the downstream markets (e.g. Goodwin and Piggott, 2001; Abdulai, 2002), there have been studies which identified the wholesale or the retail market as causal ones for meats (e.g. Bernard and Willett, 1996; Tiffin and Dawson, 2000).

Here, to determine causal markets we rely on the leveraged bootstrap simulation test of causality proposed by Hacker and Hatemi (2012) which produces critical values that are not sensitive to non-normal errors and to time-varying volatility. The (bivariate) test has been applied to two pairs of prices, namely, (lpf, lpw) and (lpw, lpr). Table 3 presents the results. For the pair (lpf, $l p w)$ and at all reasonable levels of significance, the causal order flows uni-directionally forward from the farm to the wholesale level (wholesalers adjust to shocks in farm prices while the effects of wholesale level shocks are largely confined to the wholesale market). For the pair (lpw, lpr) and at the $5 \%$ level or less, causality turns out to be uni- directional as well (retailers adjust to shocks in the wholesale level while the effects retail level shocks are largely confined to the retail market). Our results with regard to the causal order, therefore, are consistent with the bulk of earlier empirical evidence according to which meat prices are likely to be established at the upward level of the supply chain and to flow to the downward levels.

[Table 3 about here] 
Based on the findings of the causality tests, the search of evidence for price transmission asymmetry is confined to two directions, namely, farm to wholesale and wholesale to retail. To this end, the following general form NARDL models have been estimated:

$$
\begin{aligned}
& \Delta l p w_{t}=a_{0}+\rho l p w_{t-1}+\theta^{+} l p f_{t-1}^{+}+\theta^{-} l p f_{t-1}^{-}+\sum_{j=1}^{p-1} \alpha_{j} \Delta l p w_{t-j}+\sum_{j=0}^{q-1} \pi_{j}^{+} \Delta l p f_{t-j}^{+}+\sum_{j=0}^{q-1} \pi_{j}^{-} \Delta l p f_{t-j}^{-}+e_{t} \text { (7) } \\
& \Delta l p r_{t}=a_{0}+\rho l p r_{t-1}+\theta^{+} l p w_{t-1}^{+}+\theta^{-} l p w_{t-1}^{-}+\sum_{j=1}^{p-1} \alpha_{j} \Delta l p r_{t-i}+\sum_{j=0}^{q-1} \pi_{j}^{+} \Delta l p w_{t-j}^{+}+\sum_{j=0}^{q-1} \pi_{j}^{-} \Delta l p w_{t-j}^{-}+e_{t} \text { (8) }
\end{aligned}
$$

where, $l p f^{+}, l p f^{-}, l p w^{+}, l p w^{-}$are partial sums of positive and negative changes in $l p f$ and $l p w$, respectively. Model (7) relates to the price transmission from the farm to the wholesale level and model (8) to that from the wholesale to retail. The lag order has been determined following the general-to-specific approach (e.g. Greenwood-Nimmo and Shin, 2013a; Greenwood-Nimmo et al., 2013b; Shin et al., 2014). In particular, the preferred specification in each case has been selected by starting with $\max q=\max p=$ 12 and dropping all the insignificant regressors with a 5\% unidirectional decision rule. The inclusion of insignificant lags is likely to lead to inaccuracies in the estimation and may introduce noise into the dynamic multipliers.

Table 4 presents the test results for asymmetric cointegration. For both models (7) and (8), the $F_{P S S}$, the $W_{P S S}$ and the $t_{B D M}$ statistics reject the null hypothesis of no cointegration at any reasonable level of significance. Note that, following Shin et al. (2014), we have adopted the conservative approach to the choice of critical values by employing $k=1$ in testing for the null. ${ }^{6}$

\section{[Table 4 about here]}

Table 5 presents the test results for long- and short-run ${ }^{7}$ symmetry. The Wald test strongly rejects the null of long-run symmetry for the price pair (lpf, lpw); it does not,

\footnotetext{
${ }^{6}$ The critical values used here have been obtained from Pesaran et al. (2001) and Pesaran and Pesaran (2009) and were generated for sample sizes of 500 and 1000 observations. The null hypothesis of no cointegration is rejected even when we use the Narayan (2005, p.1988) higher critical values for the bounds $F$-test which are generated for smaller sample sizes of 30 to 80 observations.

${ }^{7}$ As the earlier relevant empirical works employing the NARDL model, we consider the less restrictive additive case of symmetry, i.e., $\sum_{j=0}^{q-1} \pi_{j}^{+}=\sum_{j=0}^{q-1} \pi_{j}^{-}$.
} 
however, rejects the null of short-run symmetry for the same pair. One may conclude, therefore, that APT in magnitude is relevant for the relationship between prices at the farm and at the wholesale level of the beef supply chain in the US, but APT in speed is not.

\section{[Table 5 about here]}

Greenwood-Nimmo et al. (2013b) suggest that in cases where long- or short-run symmetry turns out to be consistent with the real world data, the general NARDL model should be re-estimated with the respective symmetry condition imposed in order to avoid potential misspecification of either the long-run relationship or of the model dynamics. That suggestion has been followed here as well. In particular, the price pair (lpf, lpw) has been re-estimated with short-run symmetry imposed:

$$
\Delta l p w_{t}=a_{0}+\rho l p w_{t-1}+\theta^{+} l p f_{t-1}^{+}+\theta^{-} l p f_{t-1}^{-}+\sum_{j=1}^{p-1} \alpha_{j} \Delta l p w_{t-j}+\sum_{j=0}^{q-1} \pi_{j} \Delta l p f_{t-j}+e_{t}
$$

Tables 4 and 5 present the results for the asymmetric cointegration test and the long-run symmetry test, respectively, for model (9). The results remain the same; the null hypothesis of no cointegration is again rejected and APT in magnitude is still present for the price pair (lpf, lpw).

Regarding the pair (lpw, lpr), the Wald test strongly rejects the null of long-run symmetry and also rejects (at the $1 \%$ level or less) the null of short-run symmetry. One may conclude, therefore, that both APT in magnitude and APT in speed are relevant for the relationship between prices at the wholesale and at the retail level of the beef supply chain in the US.

Table 6 presents the parameter estimates of the models selected from the tests applied above. It also presents (at its lower part) diagnostic tests which are quite satisfactory. Moreover, Figs. 2 and 3 display the outcomes of the cumulative sum (CUSUM) test (Brown et al., 1975) for the selected NARDL models. There is no statistical evidence whatsoever of parameter instability.

[Table 6 about here]

[Figs. 2 and 3 about here]

The estimate of the long-run coefficient $\beta^{+}$for the price pair (lpf, lpw) equals 0.769 while that of the coefficient $\beta^{-}$equals 0.734 . Therefore, a $1 \%$ increase (decrease) 
in the farm price leads to a $0.769 \%(0.734 \%)$ increase (decrease) in the wholesale price; that is, in the long-run, positive shocks in the farm prices are transmitted to the wholesale level with greater intensity compared to negative ones. In particular, the transmission elasticity of positive price shocks at the farm level is 3.5 percentage points higher than that of negative price shocks. In the presence of market power, this type of long-run APT is consistent with a price transmission function which is convex in (logarithmic) prices. Azzam (1999) showed that when the power lies with the sellers, strict concavity of the aggregate demand function implies strict convexity of the price transmission function. Xia (2009), using a more general model, showed that buyer power is more important relative to seller power in determining the shape of a price transmission function (and, in turn, the extent of the APT in magnitude). According to Xia's (2009) results a strictly concave (convex) aggregate supply function is associated with a strictly convex (concave) price transmission function.

The dynamic multipliers allow us to trace out the evolution of a price at a given level of the supply chain following a shock to a price at another level of it, providing in this way a picture of the path to the new equilibrium. Fig. 4 presents the dynamic multipliers for the price transmission from the farm to the wholesale level. We observe that wholesale prices respond at the same rate, in the short-run, to farm price increases and decreases; the equilibrium correction is achieved after nearly 20 months. The longrun effect, however, as depicted by the asymmetry line of a price increase at the farm level is larger than that of a price decrease. The behaviour of the dynamic multiplier is consistent with short-run symmetry and long-run asymmetry.

[Fig. 4 about here]

The estimate of the long-run coefficient $\beta^{+}$for the price pair (lpw, lpr) equals 0.670 while that of the coefficient $\beta^{-}$equals 0.594 (Table 6). Therefore, a $1 \%$ increase (decrease) in the wholesale price leads to a $0.670 \%(0.594 \%)$ increase (decrease) in the retail price meaning that in the long-run, positive shocks in the wholesale prices are transmitted to the retail level with greater intensity compared to negative ones. In particular, the transmission elasticity of positive price shocks at the wholesale level is 7.6 percentage points higher than that of negative price shocks. Again, in the presence of 
market power, this type of long-run APT is consistent with a price transmission function which is convex in (logarithmic) prices.

Fig. 5 presents the dynamic multipliers for the price transmission from the wholesale to the retail level. We observe that (with the exception of the first few months) retail prices respond at almost the same rate to positive and negative shocks to wholesale prices. The magnitude, however, of adjustment is larger for positive shocks with the equilibrium correction being achieved after nearly 24 months. Clearly, the effect of a positive shock dominates that of a negative one in both the short as well as in the longrun. The behavior of dynamic multipliers is consistent with both short- and long-run asymmetry.

\section{[Fig. 5 about here]}

When the long-run price transmission elasticity of positive shocks exceeds that of negative ones the result is an increase in the margin between the downstream and the upstream price and/or an increase in the ratio of the two prices. The evolution of the price margins and the price ratios in the beef supply chain of the US is largely consistent with the transmission elasticities reported above. Specifically, in the second half of the sample, the margin between wholesale and farm price is 34 cents while in the first half it is only 22 cents (both on the average); in the second half of the sample, the margin between the retail and the wholesale prices is 164 while in the first half it is only 89 (both on the average). With respect to the price ratios, the wholesale to farm remained relatively stable while the retail to wholesale has risen from 1.4 in the first half of the sample to 1.7 in the second half (both on the average). The prices at the different levels of the beef supply chain in the US appear to be drifting apart and this tendency is much stronger for the pair retail-wholesale where the difference between the price transmission elasticities is twice as that for the pair farm-wholesale.

There is a rather small number of empirical works which have attempted to investigate both short- and long-run price transmission asymmetry in agri-food markets. Their results appear to vary depending on the type of data used (monthly/weekly), the period covered, and the methods employed. Zhang et al. (1995) reported ATP in speed but not in magnitude for the US peanuts market; Lass (2005) found evidence of both APT in magnitude and APT in speed for the milk chain in the Northeast (US). Those two 
studies relied on the so called pre-cointegration techniques. Gervais (2011), using the Smooth Transition Cointegration approach, found evidence in favour of long-run transmission asymmetry in the relationship between prices at the farm and at the retail level of the US pork supply chain but no evidence of short-run asymmetry. Finally, Emmanouilides and Fousekis (2015), using the statistical tool of copulas, concluded that extreme positive price shocks are more likely to be transmitted along the US beef supply chain compared to extreme negative ones. Their results are certainly in line with the findings of the present work.

At the lower level of the US beef supply chain, are the primary producers. Because vertical integration in the US beef industry is still limited, primary producers are small and independent; as such, they are unlikely to have influence on the price formation and on the distribution of the value added along the chain (Lowe and Gereffi, 2009). At the second level, are the beef packing firms; the CR4 ratio in the US beef packing is over 0.8 suggesting that beef processors are likely to have a high degree of leverage. At the upper level of the beef supply chain (retailing, food service) there is considerable degree concentration and firms with significant name recognition and, thus, with potential for market power as well.

The empirical results that price shocks flow uni-directionally from the farm level forward and that the long-run transmission elasticity for positive price shocks is higher than that for negative price shocks indicate that wholesalers (beef packers) enjoy an advantage over primary producers; their gross margin is more likely to remain the same following a price increase at the farm level and it is more likely to expand following a price decrease at the farm level. For exactly the same reasons, retailers appear to enjoy an advantage over beef packers. The latter appears to be in line with the widely acceptable perception about contemporary food supply chains that retailers are gaining bargaining power at the expense of processors (European Commission, 2009; Saitone and Sexton, 2012). Given the estimated patterns of price transmission, final consumers of beef are more likely to feel an increase of prices in upstream market levels rather than a decrease.

\section{Conclusions}


Increased concentration at the different parts of food supply chains has long attracted the attention of researchers and policy makers because of its potential welfare implications. Price inertia and incomplete pass-through impair market efficiency and prevent consumers (primary producers) from reaping the benefits from price decreases at an upstream (increases at a downstream) level. The overwhelming majority of empirical works on the topic has focused on asymmetry in the speed of price transmission paying little attention to asymmetry in magnitude. This has been an important limitation. Under asymmetry in speed, positive and negative shocks to prices at a given market level eventually pass to other market levels (although shocks of different signs have different times of transmission/follow different adjustment paths to the equilibrium). Under asymmetry in magnitude, prices at a given part of the supply chain do not return to the same level after equivalent positive and negative shocks to prices in another part of it; as a result, long-run margins and price ratios are affected.

The objective of the present work has been to investigate price transmission asymmetry (both in magnitude and in speed) for the US beef supply chain. This has been pursued using the recently proposed NARDL model (which allows prices to be tied by an asymmetric long-run relationship), and monthly data available by the ERS-USDA. Our empirical findings indicate the presence of asymmetry in magnitude for the pair of markets farm-wholesale and the presence of both asymmetry in speed and asymmetry in magnitude for the pair of markets wholesale-retail. The degree of long-run asymmetry (as captured by the respective differences in price transmission elasticities for positive and negative price shocks) is far more important for shocks emanating from the wholesale level rather than for shocks emanating from the farm level.

Overall, the empirical results suggest that processors (beef packers) enjoy a certain advantage over primary producers (cow/calf operators, stocker operators, feedlot operators) and that retailers enjoy a certain advantage over processors; also, final consumers are more likely to experience a decrease in their surplus from a price increase rather than to experience an increase in their surplus from a price decrease upstream.

Our findings, viewed in the light of the widening of margins along the beef supply chain over the last 20 years and the relevant theoretical contributions (e.g. Azzam, 1999; Xia, 2009) which link the convexity of price transmission functions to the possession of 
buyer or seller power, appear to raise certain concerns about the efficiency of the beef supply chain in the US. They should, however, be interpreted with care for several reasons:

(a) The empirical analysis here relies on price data only. As such, it allows us to test for the presence of price transmission asymmetry and to measure its degree but it does not help us to identify the causes behind it. This of course, is a problem common to all earlier studies mentioned above.

(b) The widening of margins over time is not necessarily the outcome the presence of market power; it may be observed under perfect competition as well (Garder, 1975). Moreover, as shown by Brester et al. (2009) statistics like the FS (farmers' share in the food dollar) do not really contain information about the primary producers' welfare.

(c) Horizontal consolidation in beef processing and retailing has been driven by the desire of firms to exploit economies of scale and economies of scope. A number of empirical works based on New Empirical Industrial Organization (NEIO) models found that despite the high and rising levels of consolidation in red-meat processing, departures from competitive pricing were small and that often times efficiency gains from concentration outweighed any losses from market power (e.g. Ward, 2010; Saitone and Sexton, 2012).

(d) Finally, although the NARDL model has certain advantages, it has its limitations as well. In particular, by the very definition of positive and negative shocks the NARDL assumes implicitly a zero threshold. Granger and Yoon (2002) argue that the use of a zero threshold makes the interpretation of the estimation results easy and natural. In certain circumstances, however, that assumption may be restrictive. Allowing for an endogenously determined threshold value will increase the flexibility of the NARDL model and, thus, its attractiveness relative to alternative approaches. This is a potentially interesting avenue for future research.

\section{References}

Abdulai, A. (2002). Using threshold cointegration to estimate asymmetric price transmission in the Swiss pork market. Applied Economics, 34(6), 679-687. 
Atil, A., Lahiani, A. and Nguyen, D.C. (2014). Asymmetric and nonlinear pass-through of crude oil prices to gasoline and natural gas prices. Energy Policy, 65, 567-573.

Azzam, A.M. (1999). Asymmetry and rigidity in farm-retail price transmission. American Journal of Agricultural Economics, 81(3), 525-533.

Balcombe, K., Bailey, A. and Brooks, J. (2007). Threshold effects in price transmission: The case of Brazilian wheat, maize and soya prices. American Journal of Agricultural Economics, 89(2), pp. 308-323.

Banerjee, A., Dolado, J. and Mestre, R. (1998). Error-correction mechanism tests for cointegration in a single-equation framework. Journal of Time Series Analysis, 19(3), 267-283.

Barrett, C. B. and Li, J. R. (2002). Distinguishing between equilibrium and integration in spatial price analysis. American Journal of Agricultural Economics, 84(2), pp. 292-307.

Ben-Kaabia and Gil, J. (2007). Asymmetric price transmission in the Spanish lamb sector. European Review of Agricultural Economics, 34(1), 53-80.

Bernard, J.C. and Willet, L. (1996). Asymmetric price relationships in the U.S. broiler industry. Journal of Agricultural and Applied Economics, 28(2), 279-289.

Brester, G., Marsh, J., and Atwood, J. (2009). Evaluating farmer's share -of-the-retaildollar statistic. Journal of Agricultural and Resource Economics, 32, 231-236.

Brown, R. L., Durbin, J. and Evans, J.M. (1975). Techniques for testing the constancy of regression relationships over time. Journal of The Royal Statistical Society. Series B (Methodological), 37(2), 149-192.

Choi, I. and Saikkonen, P. (2004) Testing linearity in cointegrating smooth transition regressions. Econometrics Journal, 7(2), 341-65.

Delatte, A.-L. and Lopez-Villavicencio, A. (2012). Asymmetric exchange rate passthrough: Evidence from major countries. Journal of Macroeconomics, 34(3), 833844.

Elliott, G., Rothenberg, T.J. and Stock, J.H. (1996). Efficient tests for an autoregressive unit root. Econometrica, 64(4), 813-836.

Emmanouilides, C., and Fousekis, P. (2015). Vertical price dependence structures: copula-based evidence from the beef supply chain in the US. European Review of Agricultural Economics, 42(1), 77-97.

European Commision (2009). Analysis of price transmission along the food supply chain in the EU. Commision Staff Working Document, SEC 1450. Available at: http://ec.europa.eu/economy_finance/publications/publication16067_en.pdf

Frey, G. and Manera, M. (2007). Econometric models of asymmetric price transmission. Journal of Economic Surveys, 21(2), 349-415.

Gardner, B. (1975). The farm retail price spread in a competitive food industry. American Journal of Agricultural Economics, 57(3), 399-409.

Gervais, J.P. (2011). Disentangling nonlinearities in the long- and the short-run price relationships: An application to the US hog/pork supply chain. Applied Economics, 43(12), 1497-1510.

GIPSA (2007). Livestock and Meat Marketing Study. Available at: http://www.gipsa.usda.gov/psp/publication/live_meat_market.aspx

Gonzalo, J. and Pitarakis, J. (2006). Threshold effects in cointegrating relationships. Oxford Bulletin of Economics and Statistics, 68 (Supplement 1), 813-833. 
Goodwin, B. and Piggott, N. (2001). Spatial market integration in the presence of threshold effects. American Journal of Agricultural Economics, 83(2), 302-317.

Goodwin, B.K. and Harper, D.C. (2000). Price transmission, threshold behavior, and asymmetric adjustments in the U.S. pork sector. Journal of Agriculture and Applied Economics, 32(3), 543-553.

Goodwin, B.K. and Holt, M.T. (1999). Price transmission and asymmetric adjustment in the U.S. beef sector. American Journal of Agricultural Economics, 81(3), 630637.

Goshray, A. (2010). The extent of the world coffee market. Bulletin of Economic Research, 62(1), 97-107.

Granger, C.W.J. and Yoon, G. (2002). Hidden Cointegration. Working Paper No. 200202, University of California, San Diego.

Greenwood-Nimmo, M. and Shin, Y. (2013a). Taxation and the asymmetric adjustment of selected retail energy prices in the UK. Economics Letters, 121(3), 411-416.

Greenwood-Nimmo, M., Shin, Y. and van Treeck, T. (2013b). The decoupling of monetary policy from long-term interest rates in the U.S. and Germany. Available at: http://ssrn.com/abstract=1894621.

Hacker, R.S. and Hatemi-J, A. (2010). HHcte: GAUSS module to apply a bootstrap test for causality with endogenous lag order. Statistical Software Components No. G00012, Boston College Department of Economics.

Hacker, R.S. and Hatemi-J, A. (2012). A bootstrap test for causality with endogenous lag length choice: Theory and application in finance, Journal of Economic Studies, 39(2), 144-160.

Hatemi-J, A. (2003). A new method to choose optimal lag order in stable and unstable VAR models. Applied Economics Letters, 10(3), 135-137.

Hatemi-J, A. (2008). Forecasting properties of a new method to determine optimal lag order in stable and unstable VAR models. Applied Economics Letters, 15(4), 239243.

Houck, J.P. (1977). An approach to specifying and estimating nonreversible functions. American Journal of Agricultural Economics, 59, 570-572.

Katrakilidis, C. and Trachanas, E. (2012). What drives housing price dynamics in Greece? New evidence from asymmetric ARDL cointegration. Economic Modelling, 29(4), 1064-1069.

Kinnucan, H.W. and Forker, O.D. (1987). Asymmetry in farm-retail price transmission for major dairy products. American Journal of Agricultural Economics, 69(2), 285-292.

Lass, D. (2005). Asymmetric response of retail meat prices revisited. Agribusiness, 21(4), 493-508.

Lee, J. and Strazicich, M.C. (2004). Minimum LM unit root test with one structural break. Discussion Paper. Boone, Appalachian State University.

Lowe, M. and G. Gereffi (2009). A value chain analysis of the U.S. beef and dairy industries. Center on globalization, governance \& competitiveness. Duke University. Available at: http://www.cggc.duke.edu/environment/valuechainanalysis/CGGC_BeefDairy Report_2-16-09.pdf 
Meyer, J. and von Cramon-Taubadel, S. (2004). Asymmetric price transmission: a survey. Journal of Agricultural Economics, 55(3), 581-611.

Narayan, P.K. (2005). The saving and investment nexus for China: evidence from cointegration tests. Applied Economics, 37(17), 1979-1990.

Narayan, P.K. and Sharma, S.S. (2015). Does data frequency matter for the impact of forward premium on spot exchange rate? International Review of Financial Analysis, 39, 45-53.

Pesaran, B. and Pesaran, M.H. (2009). Time series econometrics using Microfit 5.0. Oxford University Press, Oxford.

Pesaran, M.H. and Shin, Y. (1999). An autoregressive distributed lag modeling approach to cointegration analysis. In S. Strøm (Ed.), Econometrics and Economic Theory in the 20th Century: The Ragnar Frisch Centennial Symposium. Cambridge University Press, Cambridge.

Pesaran, M.H., Shin, Y. and Smith, R.J. (2001). Bounds testing approaches to the analysis of level relationships. Journal of Applied Econometrics, 16(3), 289-326.

Phillips, P.C.B. and Perron, P. (1988). Testing for a unit root in time series regression. Biometrika, 75(2), 335-345.

Romilly, P., Song, H. and Liu, X. (2001). Car ownership and use in Britain: A comparison of the empirical results of alternative cointegration estimation methods and forecasts. Applied Economics, 33(4), 1803-1818.

Saitone, T., and Sexton, R. (2012). Market structure and competition in the US food industries. Implications for the 2012 Farm Bill. Available at: http://www.aei.org/files/2012/04/02/-market-structure-and-competition-in-theus-food-industries_102234192168.pdf

Serra, T. and Goodwin, B. K. (2003). Price transmission and asymmetric adjustment in the Spanish dairy industry. Applied Economics, 35(18), 1889-1899.

Shin, Y., Yu, B. and Greenwood-Nimmo, M. (2014). Modelling asymmetric cointegration and dynamic multipliers in a nonlinear ARDL framework. In Festschrift in honor of Peter Schmidt: Econometric methods and applications, edited by W. C. Horrace and R. C. Sickles. New York: Springer Science And Business Media, 281-314.

Tiffin, R., and P. Dawson (2000). Structural breaks, cointegration, and the farm-retail price spread for lamb. Applied Economics, 32(10), 1281-1286.

Tweeten, L.G. and Quance, C.L. (1969). Positivistic measures of aggregate supply elasticities: Some new approaches. American Journal of Agricultural Economics, 51(2), 342-352

Varva, P, and Goodwin, P. (2005). Analysis of price transmission along the food chain.

OECD Food, Agriculture, and Fisheries. Working Paper No 3.

Verheven, F. (2013). Exchange rate nonlinearities in EMU exports to the US, Economic Modelling, 32, 66-76.

von Cramon-Taubadel, S. and Fahlbusch, S. (1994). Identifying asymmetric price transmission with error correction models. Poster Session, EAAE European Seminar in Reading.

Ward, C. (2010). Assessing competition in the U.S. beef packing industry. Choices: The Magazine of Food, Farm and Resource Issues, 25(2), $2^{\text {nd }}$ Quarter, Article 3. Available at: http://www.choicesmagazine.org/magazine/pdf/article_121.pdf 
Ward, R.W. (1982). Asymmetry in retail, wholesale and shipping point pricing for fresh vegetables. American Journal of Agricultural Economics, 64(2), 205-212

Wolffram, R. (1971). Positivistic measures of aggregate supply elasticities: Some new approaches-some critical notes. American Journal of Agricultural Economics, 53(2), 356-359

Xia, T. (2009). Asymmetric price transmission, market power and supply and demand curvature. Journal of Agricultural and Food Industrial Organization, 7, Article 6.

Zhang, P., Fletcher, S.M. and Carley, D.H. (1995). Peanut price transmission asymmetry in peanut butter. Agribusiness, 11(1), 13-20.

Zivot, E. and Andrews, D.W.K. (1992). Further evidence on the great crash, the oil-price shock, and the unit-root hypothesis. Journal of Business and Economic Statistics 20(1), 25-44. 


\section{Tables}

Table 1

Phillips-Perron and DF-GLS unit root tests

\begin{tabular}{lllll}
\hline \multirow{2}{*}{ Variable } & Phillips-Perron & \multicolumn{3}{l}{ DF-GLS } \\
\cline { 2 - 5 } & $\mathrm{C}$ & $\mathrm{C} / \mathrm{T}$ & $\mathrm{C}$ & $\mathrm{C} / \mathrm{T}$ \\
\hline$l p f$ & 0.109 & -1.764 & $-0.173(3)$ & $-1.292(3)$ \\
$l p w$ & 0.239 & -2.357 & $0.288(3)$ & $-1.366(3)$ \\
$l p r$ & 0.458 & -1.948 & $1.473(1)$ & $-1.682(1)$ \\
$\Delta l p f$ & $-11.163^{* * *}$ & $-25.817^{* * *}$ & $-11.576(2)^{* * *}$ & $-11.268(2) * * *$ \\
$\Delta l p w$ & $-14.537 * * *$ & $-16.769 * * *$ & $-12.354(2)^{* * *}$ & $-12.138(1)^{* * *}$ \\
$\Delta l p r$ & $-13.580^{* * *}$ & $-13.607^{* * *}$ & $-2.609(6) * *$ & $-12.497(0) * * *$ \\
\hline
\end{tabular}

Note: $\Delta$ is the first difference operator.

The optimal lag structure of the PP tests is chosen based on the Newey-West bandwidth with Bartlett weights and are displayed in parentheses.

The optimal lag structure of the DF-GLS tests is chosen based on the Schwarz Information Criterion and are displayed in parentheses.

The $1 \%$ and the $5 \%$ critical values for the Phillips-Perron unit root test are -3.58, -2.93 and 4.15, -3.50 for models $\mathrm{C}$ and $\mathrm{C} / \mathrm{T}$ respectively.

The $1 \%$ and the $5 \%$ critical values for the DF-GLS test are $-2.61,-1.94$ and $-3.76,-3.18$ for models $\mathrm{C}$ and $\mathrm{C} / \mathrm{T}$, respectively.

The estimations and tests were conducted using EViews 8.0.

$* * *$ and $* *$ denote rejection of the null hypothesis of unit root at the 1 and $5 \%$ levels, respectively.

Table 2

Zivot-Andrews and LM unit root tests with one structural break

\begin{tabular}{lllllllll}
\hline & Model A & \multicolumn{7}{c}{ Model C } \\
\cline { 2 - 10 } Variables & $\begin{array}{l}\text { Zivot-Andrews } \\
\text { test statistic }\end{array}$ & $T_{B}$ & $\begin{array}{l}\text { LM test } \\
\text { statistic }\end{array}$ & $T_{B}$ & $\begin{array}{l}\text { Zivot-Andrews } \\
\text { test statistic }\end{array}$ & $T_{B}$ & $\begin{array}{l}\text { LM test } \\
\text { statistic }\end{array}$ & $T_{B}$ \\
\hline$l p f$ & $-4.118(3)$ & $1994: 05$ & $-2.335(3)$ & $2004: 02$ & $-4.295(3)$ & $1994: 05$ & $-4.874 * *(2)$ & $1995: 10$ \\
$l p w$ & $-3.741(3)$ & $1994: 05$ & $-2.650(3)$ & $1994: 04$ & $-4.387(3)$ & $1999: 01$ & $-4.198(3)$ & $1995: 05$ \\
$l p r$ & $-3.502(1)$ & $1993: 12$ & $-2.025(2)$ & $2003: 09$ & $-4.503(1)$ & $2000: 03$ & $-3.295(1)$ & $2000: 12$ \\
$\Delta l p f$ & $-11.931^{* * *}(2)$ & $2003: 12$ & $-11.180^{* * *}(1)$ & $2003: 12$ & $-11.911^{* * *}(2)$ & $2003: 12$ & $-11.303^{* * *}(2)$ & $2004: 04$ \\
$\Delta l p w$ & $-13.101^{* * *}(2)$ & $2003: 11$ & $-3.629(6)$ & $2003: 05$ & $-13.074^{* * *}(2)$ & $2003: 11$ & $-12.839 * * *(2)$ & $2011: 02$ \\
$\Delta l p r$ & $-12.726^{* * *}(1)$ & $2003: 12$ & $-13.050^{* * *}(0)$ & $2002: 11$ & $-12.699 * * *(1)$ & $2003: 12$ & $-13.127^{* * *}(0)$ & $2009: 12$ \\
\hline
\end{tabular}

Note: $\Delta$ is the first difference operator.

$T_{B}$ denotes the time of break.

Model A allows for a change in the level of the series; Model C allows for changes in the level and slope of the trend of the series.

The optimal lag structure of the Zivot and Andrews (1992) test is chosen based on the Schwarz Information Criterion and are displayed in parentheses.

The optimal lag structure of the Lee and Strazicich (2004) LM test is chosen following a general-to-specific approach, as suggested by Lee and Strazicich (2004), and are displayed in parentheses.

The critical values were obtained from Zivot and Andrews (1992) and Lee and Strazicich (2004).

The estimations and tests were conducted using RATS 8.0.

*** and $* *$ denote the rejection of the null hypothesis of a unit root at the 1 and $5 \%$ level, respectively. 
Table 3

Causality tests using the Hacker and Hatemi-J (2012) bootstrap simulation technique

\begin{tabular}{lllll}
\hline Null hypothesis & Test value & CV at 1\% & CV at 5\% & Optimal lag \\
\hline$l p w \neq>l p r$ & $122.896^{* * *}$ & 13.287 & 9.550 & 4 \\
$l p r \neq>l p w$ & 8.095 & 13.445 & 9.601 & 4 \\
$l p f \neq>l p w$ & $35.920^{* * *}$ & 11.393 & 7.806 & 3 \\
$l p w \neq>l p f$ & 2.119 & 11.942 & 8.020 & 3 \\
\hline
\end{tabular}

Note: The symbol $\neq>$ means that A does not cause B.

$\mathrm{CV}$ is an abbreviation for the bootstrap critical value.

The optimal lag length in each VAR model (excluding augmentation lag) was selected based on the Hatemi-J Criterion (Hatemi, 2003 and 2008).

The maximum lag was set to 12 .

The bootstrap simulations for the causality tests were conducted using 10000 simulations with a program code written in GAUSS that was produced by Hacker and Hatemi-J (2010).

*** denotes rejection of the null hypothesis at the $1 \%$ level.

Table 4

Bounds testing for asymmetric cointegration

\begin{tabular}{llll}
\hline & \multicolumn{2}{l}{ Farm to wholesale price transmission } & Wholesale to retail price transmission \\
\hline \multirow{2}{*}{ Statistic } & $\begin{array}{l}\text { NARDL model (7) with } \\
\text { LR and SR asymmetry }\end{array}$ & $\begin{array}{l}\text { NARDL model (9) with } \\
\text { SR symmetry imposed }\end{array}$ & $\begin{array}{l}\text { NARDL model (8) with } \\
\text { LR and SR asymmetry }\end{array}$ \\
\hline$F_{\text {PSS }}$ & $7.83^{* *}$ & $8.21^{* * *}$ & $9.28^{* * *}$ \\
$W_{P S S}$ & $23.49^{* * *}$ & $24.64^{* * *}$ & $27.86^{* * *}$ \\
$t_{\text {BDM }}$ & $-4.84^{* * *}$ & $-4.96^{* * *}$ & $-5.21^{* * *}$ \\
\hline
\end{tabular}

Note: For $k=1$ and at the 1\% (5\%) level of significance, the pair of critical values (bounds) for the $F_{P S S}$, the $W_{P S S}$ and the $t_{B D M}$ statistics are 6.84 to 7.84 (4.94 to 5.73), 14.11 to15.63 (9.86 to11.52) and -3.43 to -3.82 (-2.86 to -3.22$)$, respectively.

The critical values have been obtained from Pesaran et al. (2001) and Pesaran and Pesaran (2009).

The estimations and tests were conducted using a program code written in STATA which was produced by M. Sunder and retrieved from Matthew Greenwood-Nimmo's webpage ${ }^{8}$ and Microfit 5.0.

*** and $* *$ denote rejection of the null hypothesis of no cointegration at the 1 and $5 \%$ levels, respectively.

\footnotetext{
${ }^{8}$ http://www.greenwoodeconomics.com/
} 
Table 5

Long- and short-run symmetry tests

\begin{tabular}{llll}
\hline & Farm to wholesale price transmission & Wholesale to retail price transmission \\
\hline \multirow{2}{*}{ Statistic } & NARDL model (7) with & NARDL model (9) with & NARDL model (8) with \\
& LR and SR asymmetry & SR symmetry imposed & LR and SR asymmetry \\
\hline \multirow{2}{*}{$W_{L R}$} & $16.992^{* * *}(0.000)$ & $16.347^{* * *}(0.000)$ & $78.214^{* * *}(0.000)$ \\
$W_{S R}$ & $0.020(0.885)$ & - & $6.500^{* * *}(0.011)$ \\
\hline
\end{tabular}

Note: $W_{L R}$ refers to the Wald test for the null of long-run symmetry defined by $-\hat{\theta}^{+} / \hat{\rho}=-\hat{\theta}^{-} / \hat{\rho}$.

$W_{S R}$ refers to the Wald test for the null of the additive (weak-form) symmetry defined by

$\sum_{j=0}^{q-1} \pi_{j}^{+}=\sum_{j=0}^{q-1} \pi_{j}^{-}$.

p-values are displayed in parentheses.

The estimations and tests were conducted using a program code written in STATA which was produced by M. Sunder and retrieved from Matthew Greenwood-Nimmo's webpage.

*** denotes rejection of the null hypothesis of symmetry at the $1 \%$ level. 
Table 6

NARDL estimation results

\begin{tabular}{llllll}
\hline \multicolumn{2}{l}{ Farm to wholesale price transmission } & \multicolumn{3}{l}{ Wholesale to retail price transmission } \\
\hline \multicolumn{2}{l}{ NARDL model (9) with SR symmetry imposed } & \multicolumn{4}{l}{ NARDL model (8) with LR and SR asymmetry } \\
\hline Variable & Coefficient & Standard Error & Variable & Coefficient & Standard Error \\
\hline Constant & $1.055^{* * *}$ & 0.212 & Constant & $0.790^{* * *}$ & 0.151 \\
$l p w_{t-1}$ & $-0.202^{* * *}$ & 0.040 & $l p r_{t-1}$ & $-0.139^{* * *}$ & 0.026 \\
$l p f_{t-1}^{+}$ & $0.155^{* * *}$ & 0.033 & $l p w_{t-1}^{+}$ & $0.093^{* * *}$ & 0.018 \\
$l p f_{t-1}^{-}$ & $0.148^{* * *}$ & 0.032 & $l p w_{t-1}^{-}$ & $0.083^{* * *}$ & 0.016 \\
$\Delta l p w_{t-2}$ & $-0.172^{* * *}$ & 0.057 & $\Delta l p r_{t-2}$ & $-0.187^{* * *}$ & 0.051 \\
$\Delta l p w_{t-3}$ & $-0.118^{* * *}$ & 0.037 & $\Delta l p r_{t-4}$ & $0.114^{* *}$ & 0.049 \\
$\Delta l p w_{t-9}$ & $-0.126^{* *}$ & 0.056 & $\Delta l p r_{t-8}$ & $0.113^{* *}$ & 0.051 \\
$\Delta l p w_{t-12}$ & $0.213^{* * *}$ & 0.055 & $\Delta l p r_{t-12}$ & $0.105^{* *}$ & 0.047 \\
$\Delta l p f_{t}$ & $0.798^{* * *}$ & 0.036 & $\Delta l p w_{t}^{+}$ & $0.098^{* * *}$ & 0.035 \\
$\Delta l p f_{t-2}$ & $0.228^{* * *}$ & 0.059 & $\Delta l p w_{t-1}^{+}$ & $0.116^{* * *}$ & 0.036 \\
$\Delta l p f_{t-4}$ & $0.133^{* * *}$ & 0.039 & $\Delta l p w_{t-2}^{+}$ & $0.161^{* * *}$ & 0.034 \\
$\Delta l p f_{t-7}$ & $0.099^{* * *}$ & 0.037 & $\Delta l p w_{t-3}^{+}$ & $0.078^{* *}$ & 0.037 \\
$\Delta l p f_{t-9}$ & $0.137^{* *}$ & 0.056 & $\Delta l p w_{t-7}^{+}$ & $-0.070^{* *}$ & 0.032 \\
$\Delta l p f_{t-12}$ & $-0.230^{* * *}$ & 0.057 & $\Delta l p w_{t}^{-}$ & $0.135^{* * *}$ & 0.039 \\
& & & $\Delta l p w_{t-1}^{-}$ & $0.106^{* *}$ & 0.041 \\
& & & $\Delta l p w_{t-9}^{-}$ & $-0.094^{* *}$ & 0.037
\end{tabular}

Asymmetric Long-Run Price Transmission Elasticities

\begin{tabular}{llll}
\hline$\beta_{l p f}^{+}$ & $0.769 * * *(0.000)$ & $\beta_{l p w}^{+}$ & $0.670^{* * *}(0.000)$ \\
$\beta_{l p f}^{-}$ & $0.734^{* * *}(0.000)$ & $\beta_{l p w}^{-}$ & $0.594^{* * *}(0.000)$ \\
\hline \multicolumn{4}{l}{ Statistics } \\
\hline$R^{2}$ & 0.722 & & \\
$S C$ & $14.178(0.289)$ & $R^{2}$ & 0.479 \\
ARCH & $12.138(0.434)$ & $S C$ & $8.133(0.775)$ \\
CUSUM & $-0.590(0.555)$ & ARCH & $12.699(0.391)$ \\
\hline
\end{tabular}

Note: The superscripts “+ " and " - " denote positive and negative partial sums, respectively.

$\beta^{+}$and $\beta^{-}$are the estimated asymmetric long-run coefficients associated with positive and negative changes, respectively, defined by $\hat{\beta}^{+}=-\hat{\theta}^{+} / \hat{\rho}$ and $\hat{\beta}^{-}=-\hat{\theta}^{-} / \hat{\rho}$, respectively.

$S C$ and $A R C H$ denote LM tests for serial correlation and conditional heteroscedasticity, respectively.

p-values are displayed in parentheses.

The estimations and tests were conducted using a program code written in STATA which was produced by M. Sunder and retrieved from Matthew Greenwood-Nimmo’s webpage and Microfit 5.0.

*** and $* *$ denote significance at the 1 and $5 \%$ levels, respectively. 


\section{Figures}

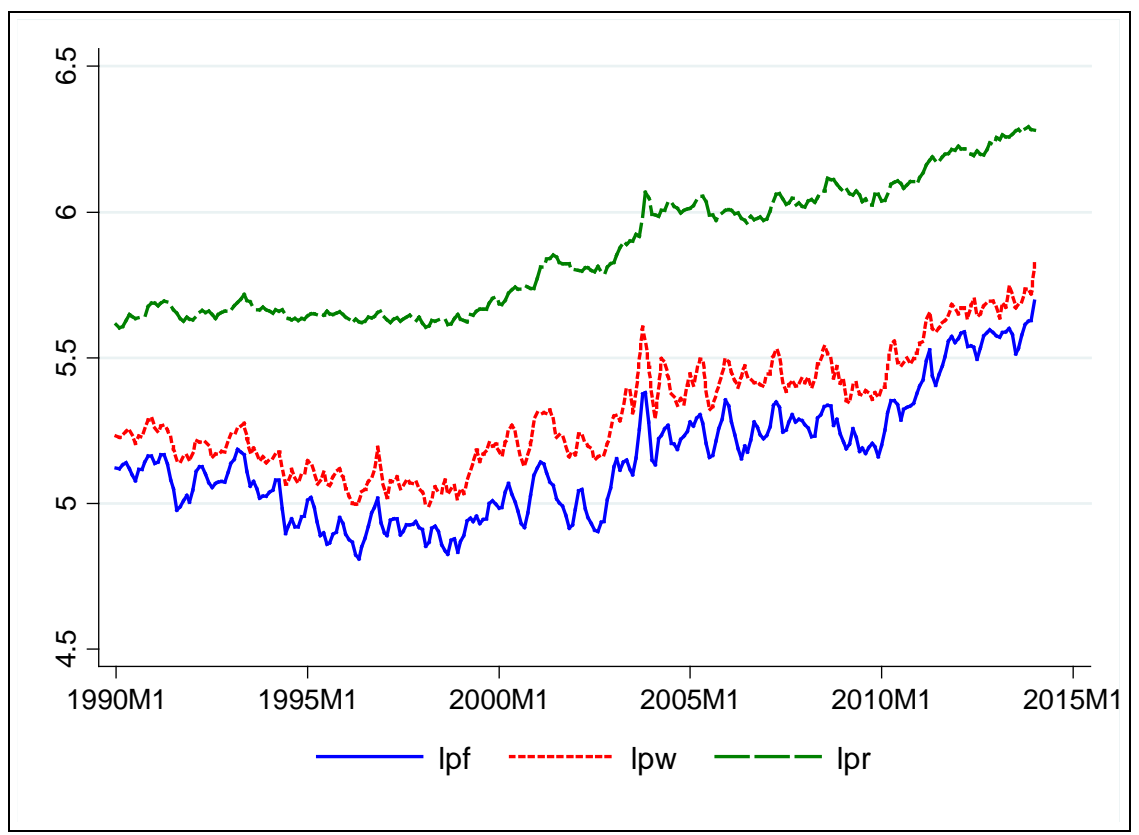

Fig. 1. The natural logarithms of farm (lpf), wholesale (lpw), and retail (lpr) prices of the US beef supply chain 


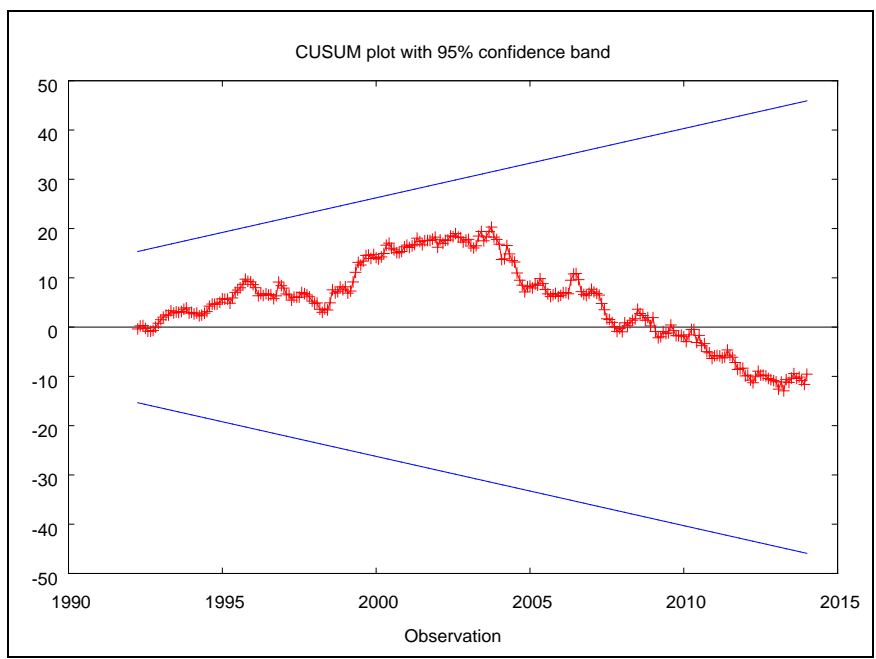

Fig. 2. Cumulative sum (CUSUM) test on NARDL model (9) with SR symmetry imposed

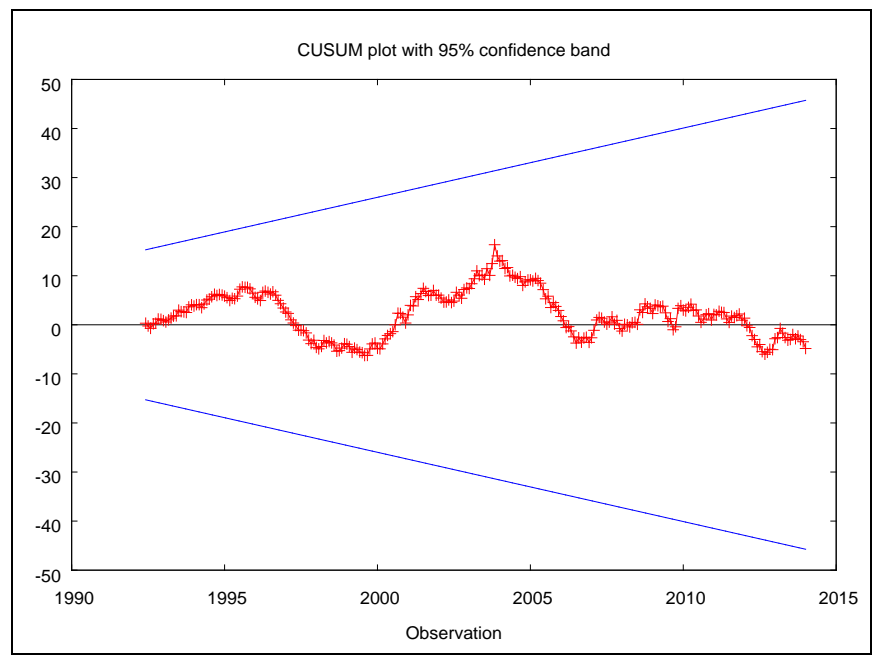

Fig. 3. Cumulative sum (CUSUM) test on NARDL model (8) with LR and SR asymmetry 


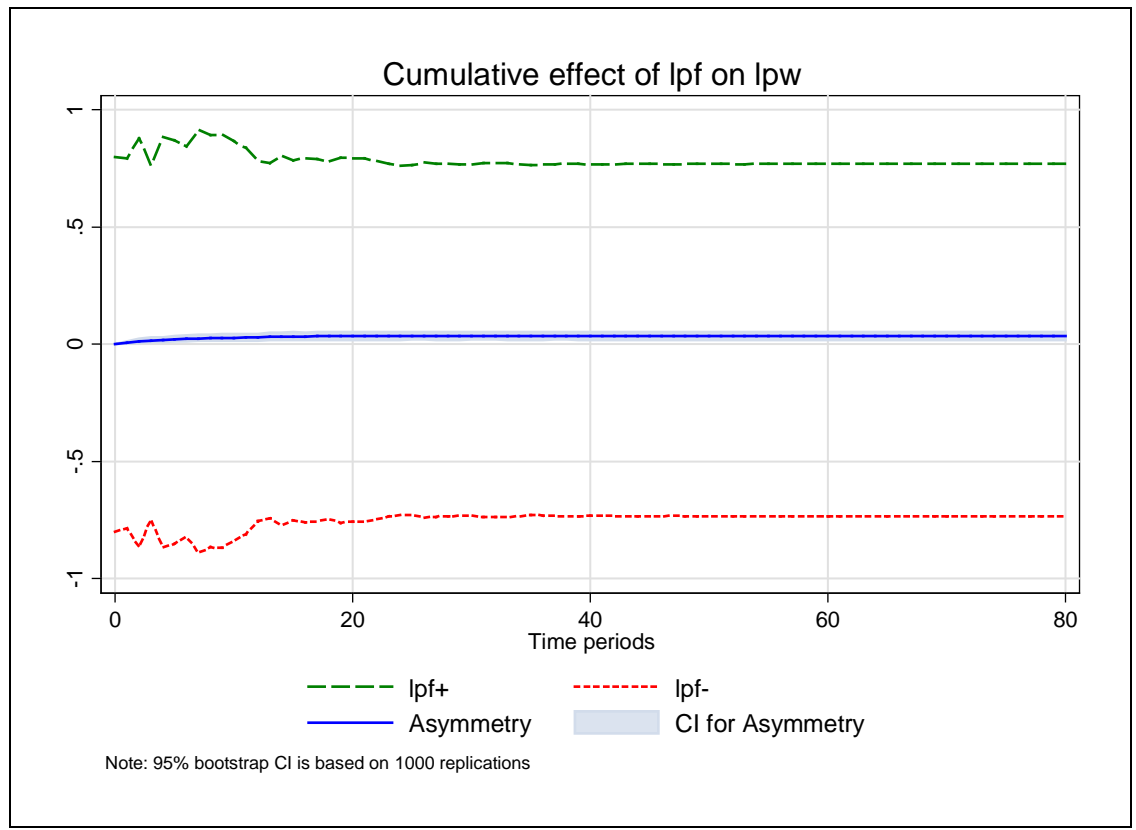

Fig. 4. Dynamic Multipliers. Farm to Wholesale Level

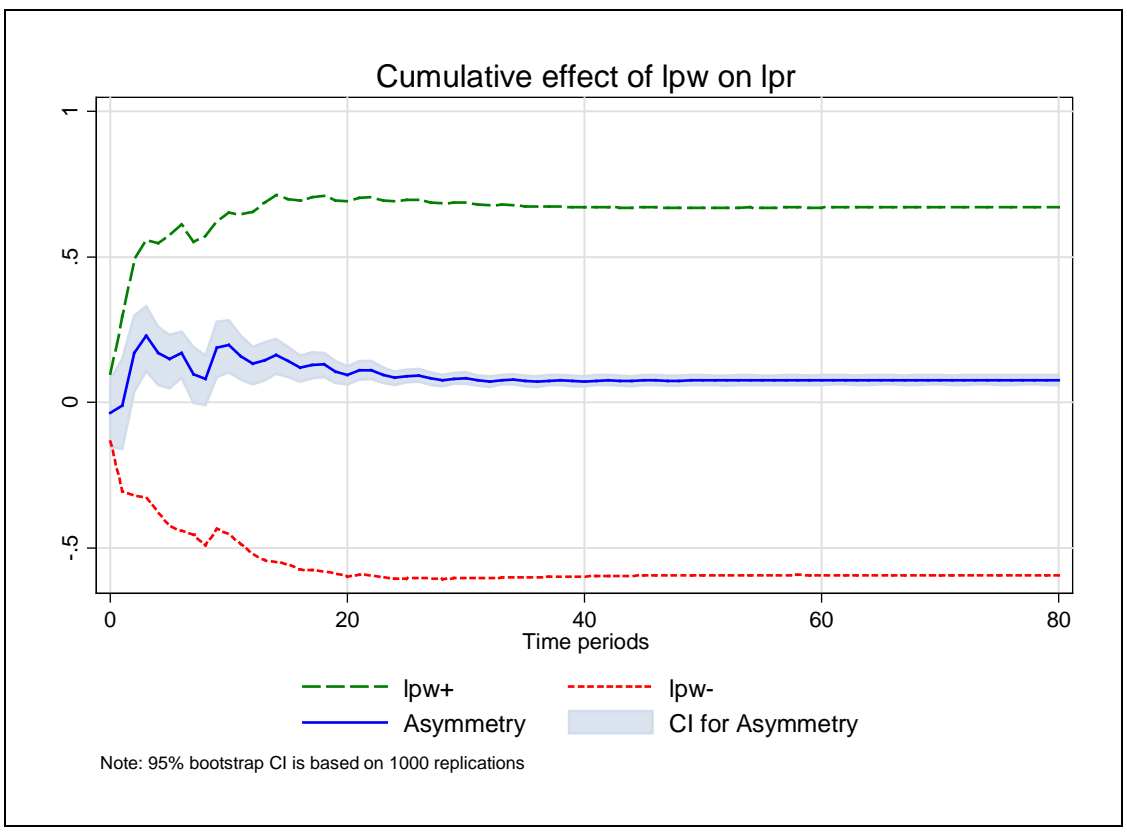

Fig. 5. Dynamic Multipliers. Wholesale to Retail Level 